\title{
REDESIGN OF AN AXIAL COMPRESSOR WITH MASS FLOW REDUCTION OF 30\%
}

\author{
VIACHESLAV ALEKSEEVICH SEDUNIN, YURII MIRONOVICH BRODOV, \\ OLEG VIACHESLAVOVICH KOMAROV, VITALIY LEONIDOVICH BLINOV, \\ ALEXANDER VLADIMIROVICH SKOROKHODOV \& SERGEY ALEKSANDROVICH SERKOV \\ Turbines and Engines Department, Ural Federal University, Russia
}

\begin{abstract}
In this paper redesign process of an axial compressor of a Gas Turbine for mechanical drive is discussed together with computational results and experimental data. The goal of the project was to reduce compressor mass flow by $30 \%$ and at the same time to increase compressor specific work by about $10 \%$. This could not be achieved by conventional methods such as re-staggering of Inlet Guide Vanes. Throughflow and CFD calculations were performed for redesigned versions. As a result an updated compressor was produced for the real engine and achieved design objectives. This paper shows how the swept area distribution along the compressor affects stage loading distribution and surge limits.

Keywords: axial compressor of gas turbine, CFD computations, meridional contours, flow path, profiling of compressor blades, verification of computational model.
\end{abstract}

\section{INTRODUCTION}

Sometimes industrial requirements can cause non-standard approaches to the engineering design. From one side, this can lead to not-the-best variant according to theoretical understanding, but from the other hand, being done in this way, it might save serious amount of funding, and therefore that non-optimality can be justified. An example of such approach is discussed in this paper.

Due to exhaust of a natural gas field at one of the customer sites a required power of a gas compressing unit dropped down by more than $30 \%$. It is known, that thermal engine, particularly gas turbine can maintain optimal efficiency only in relatively narrow range of generated power - for best modern machines it can be 70 to $105 \%$ of optimal load, for older designs this range is less than a half of that. So, operating in the range of 50 to $70 \%$ is way below the optimum, and providing that turbine's power will not go above, it sound reasonable to perform minor corrections to the flow path of axial compressor and turbines in order to reach the efficiency peak at new operating conditions. Though, it was expected to reduce the isentropic efficiency of the compressor by about $2 \%$. Similar re-design project was carried earlier on for better stage matching (see [1]).

As for Turbine Inlet Temperature (TIT), which can be used to compensate the efficiency drop, it was more or less limited, since the materials were already chosen for most of the parts. However, approximately 5\% increase in TIT was planned based on improved combustor cooling scheme. For a turbine part the approach was similar to the compressor's one. Only compressor design is presented further in this paper.

So, the project goal was to redesign the Gas Turbine engine for reduced design power by $30 \%$. This type of engine was already in operation for many years so minimum new parts as well as minimum re-machining were required. Also, the machines were located on site in remote area, so the optimum logistics was also considered.

As a result for axial compressor part the requirements were: i) to keep constant hub diameter of the flow path as it was in the datum design; ii) to reduce mass flow mainly by reducing the outer diameter of the flow path and blade height accordingly; iii) to leave rotor blades' stagger angles as it were, so only rotor tips can be machined down to the new 
dimensions. As a result, an inner casing was the only major part to be manufactured, when rotor, both rotor and stator blades, outer casing and air ducts were re-used from old machines. The stator blade's configuration allowed to easily adjust them at the new casing thanks to pivot roots design.

\section{PROBLEM DESCRIPTION}

Aerodynamic design of an axial compressor consists of several main steps starting from onedimensional stage matching along the flow path, then radial distribution of the flow (including blade twist along the span), and the third step deals with complex threedimensional flow structures such as tip leakage flows, corner separations etc. Obviously, the datum compressor already accommodated successful one- and two-dimensional designs, and the 3D approach was not applicable by the time when this particular machine was developed. Therefore, the major task of the redesign project was to maintain stage matching as it was set initially but with respect to presumably higher blockage and losses due to reduced blade height.

In general, mass flow reduction could be achieved by closing the variable inlet guide vanes (VIGV). But, firstly, the compressor inlet vanes were not designed as variable. Secondly, closed VIGV leads to reduced loading of the frontal stages; however, the project goal was to increase it. And finally, the inlet guide vanes were already far too closed at the datum machine (the outflow angle is $59^{\circ}$ from the frontal surface, when optimal range is $60.90^{\circ}$ ), and further closing by $30 \%$ of the area will convert IGV to a significant throttle.

So, vanes and blades stagger angels in axial compressor were decided to keep the same as it was for datum machine, and only swept area were adjusted for lower mass flow. From practical point it is interesting to follow how the area distribution along the flow affects the stage loading and surge limits of the machine.

In present design the axial compressor has constant hub diameter with shroud contour being described by three lines, so the flow path has conical shape (Fig. 1). Stator part consists of outer and inner casings, and inner casings can be removed, re-machined and replaced. Whereas the forged rotor with cylindrical shape has tangential grooves for blade roots and is unlikely to be re-machined.

So, the most important question is the approach to mass flow reduction. The rotor diameter remains the same, so does the blade' stagger angles, whereas the tip diameter (or so-called casing diameter) is to be cut by appropriate distance. This way was chosen by customer due to its technological simplicity and more robust design, since the rotor assembly remains the same with trimmed blades and casing space plates were introduced in the non-rotating part with no need of re-staggering.

It is well known that similar kind of studies is common in centrifugal compressors where the shroud control allows to expand or move the compressor characteristic along the mass flow axis and also change its efficiency and stall margin [2]. For multistage axial compressor design several papers were also presented [3]-[5]. In [3] a rich literature overview is given.

\section{MERIDIONAL SHAPE ADAPTATION}

When a compressor is made of a consequence of similar stages (in literature it is called the repeating stage concept), there are two ways of matching the stages together: adjusting stagger angle of rotor and stator blades or adjusting the blade height in order to maintain constant flow angles throughout the flow path. Normally, final configuration will combine both ways. 


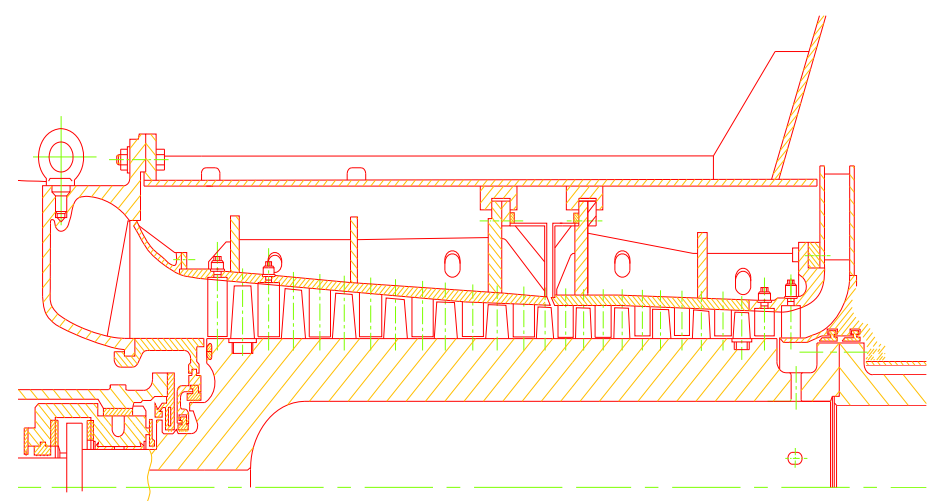

Figure 1: Axial compressor cross-section.

The value of certain adjustments is dictated by axial speed of the core flow, which is, in turn, a function of pressure ratio of upcoming stages, effective spanwise blockage and compressor efficiency. More detailed approach can be found in [6].

So, the interesting case appear when staggering is fixed by existing blades and roots design, but the flowpath meridional profile is the only parameter to be adjusted. In order to make this possible, one should be able, first, to develop adequate model for predicting the blockage and efficiency (and, as a consequence, loading distribution along the axis). The second is to apply the model for further blade height reduction, where the combination of profile and secondary loss became crucial.

The very first iteration, which is natively expected, was to imply the proportional cut with the swept area of new compressor defined as:

$$
A_{\text {new }}=A_{d a t} \cdot \frac{G_{\text {new }}}{G_{\text {dat }}} \cdot \frac{\rho_{\text {dat }}}{\rho_{\text {new }}} \cdot \frac{B_{\text {dat }}}{B_{\text {new }}},
$$

where A is the swept area of each stage, $\rho$ - air density and B - effective blockage. So the mass flow ratio is corrected by change in density and blockage, where the former is a function of upcoming stages' pressure rise and efficiency, and the latter mainly depends on the endwall effects.

The end-wall losses for the $30 \%$ shorter blade will obviously be higher when the actual size of the radial gap remains the same in absolute value. But the amount of change is not that clear.

So, the problem is how to obtain and implement new pressure loss and blockage corrections in order to achieve aerodynamic similarity with the datum design. The only possible solution by that time was to have extensive CFD analysis in order to estimate compressor behavior with reduced blade height. The two most uncertain questions were: i) how good is applied CFD method in reproducing endwall flow features, and therefore losses and blockage and ii) how univocal is a correspondence between gradient in stage swept area and loading distribution? In other words, since the endwall blockage and the losses are functions of stage operating point, then could it be the case that by, say, reducing the swept area even steeper, one can reduce the blockage to the level of the datum design and, therefore, reach another equally good configuration. 
These two questions are just raised here, but have no clear answer, so it was decided to do computational study in relatively wide range of swept area configurations along the flow path. On Fig. 2 different variations of shroud contours are presented as a result of different design approaches.

After couple of iterations three most suitable configurations were chosen: V2, V4 and V7. The V2 is scaled down by $25 \%$ at the inlet and $35 \%$ at the outlet with the intention to increase loading of the frontal stages, so less efficient rear stages would do less compression work. The only difference between V4 and V7 is different slope at rear stages, where V7 has simply scaled down swept area (reduced by 30\%), and at V4 the last stage swept area reduced by $25 \%$ only with linear interpolation to V7 at stage 6 , accounting for higher expected blockage.

\section{CFD CALCULATIONS AND ANALYSIS}

For CFD computations ANSYS CFX was used. Size of the element next to wall was about $\mathrm{y}^{+} \leq 100$. The total number of cells was about $2 \times 10^{6}$ cells. Turbulence model $-\mathrm{k}-\varepsilon$ standard. The interface between rows - Stage. Tip clearance dimensions were taken from "cold" geometry drawings regardless further thermal expansion of the materials. Boundary conditions were: total pressure and temperature at the inlet and static pressure at the outlet. Series of calculations were carried out with the outlet static pressure increase. Normally this approach shows good convergence at the design point and up to $10.15 \%$ above it.

Previous experience [1], [7] has shown too optimistic prediction of a mass flow comparing to the real compressor. This was explained by miss-prediction of the size of separation zones at the end-walls. However, expectations of greater mass flow proved to be wrong, and real manufactured compressor provided very close to computed value of the mass flow. Similar sort of calculations and its discussion were presented in [8], [9].

The analysis given below was performed for all variations, but for the sake of simplicity only key parameters are presented for three best variants.

Parameters at Fig. 3 are given at the design speed and also at $75 \%$ of it, which represent engine zero power conditions. On Fig. 3 the stage load distribution is presented in percentage of that for the datum compressor. For all variants the pressure ratio at the first stage (called "zero stage" due to historical process) is significantly lower, that is caused by closed inlet guide vane. This was made intentionally in order to maintain stable operation at part speed, so this approach was maintained in new machine. The rest of the stages are almost equally loaded, 7th and 8th stages at initial design are slightly overloaded. This is due to shroud

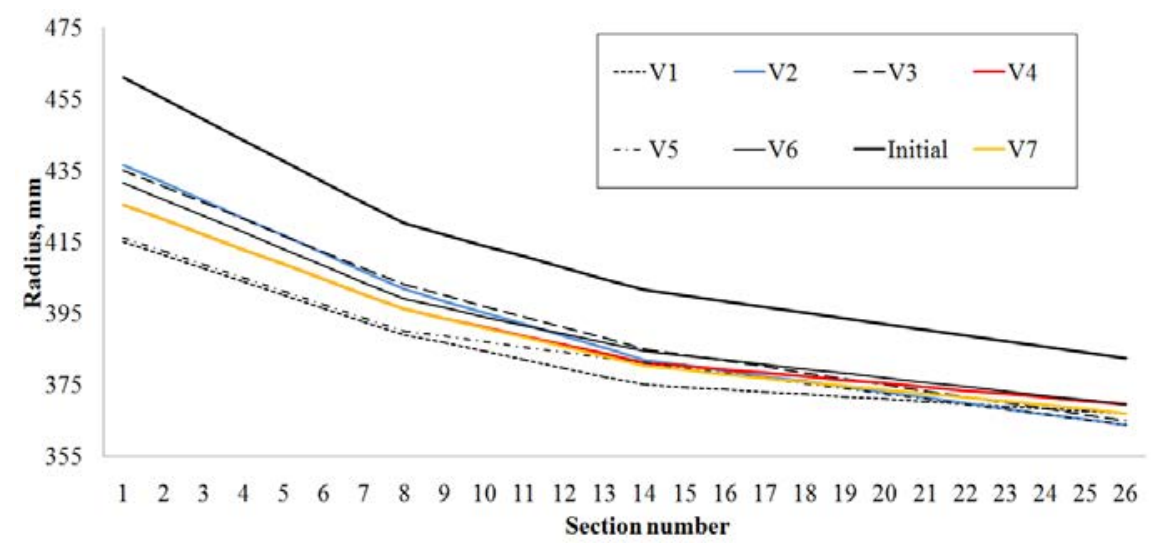

Figure 2: Shroud contours of different variations. 

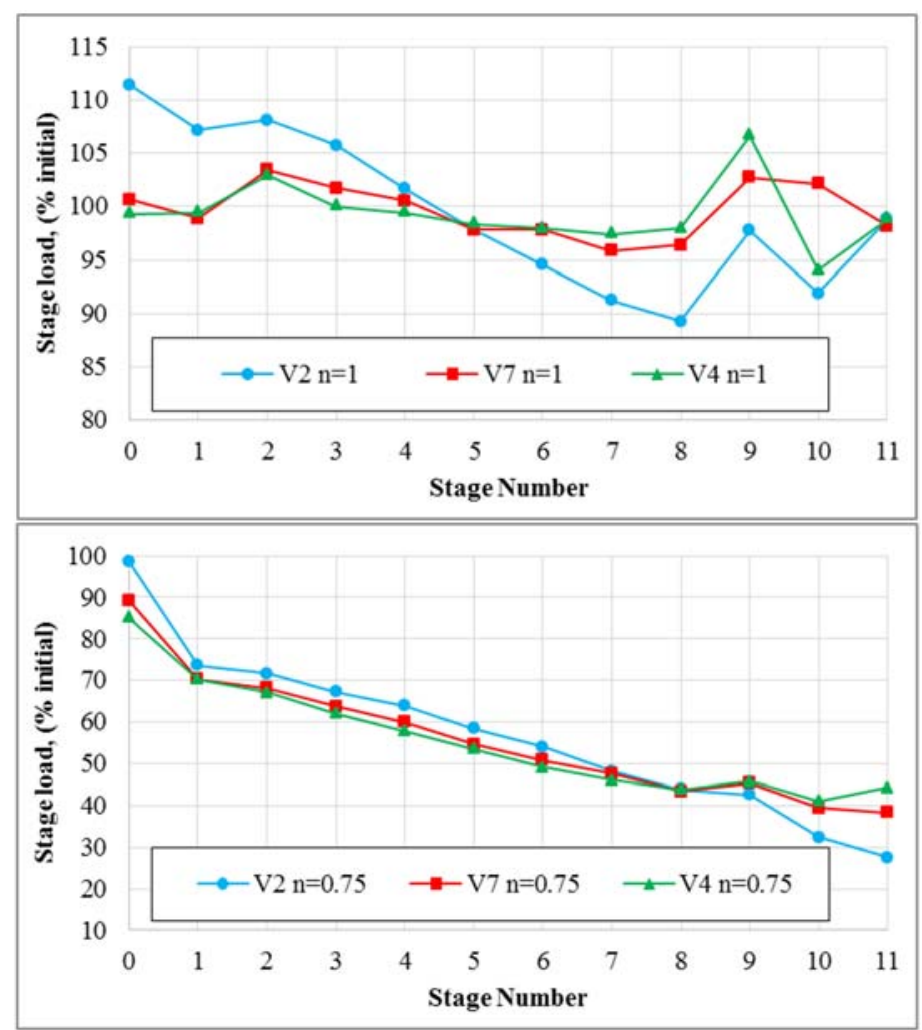

Figure 3: Load distribution along the compressor at design speed (top) and 75\% (bottom).

line break after the 6th stage, which probably caused by sudden blockage change. For versions 4 and 7 the character of the lines is the same, but for version 2 the load is reducing. Loading shift in stage 9 is another example of the blockage change, since around this stage the flow separation occurs, so the effective channel area varies a lot.

So, the intention of having overly loaded frontal stages at V2 was achieved, however, for the part load, this led to unstable operation of stage one (see Fig. 3 bottom). Speed line calculations (Fig. 5) proved that V2 has lower stall margin at 75\% speed, then versions 4 and 7. But due to frontal loaded design V2 has the highest compressor efficiency, as was expected initially.

On Fig. 4 Mach number distributions are presented for datum compressor, V2 and V4. For V4 and the initial compressor it can be seen the blue contours at last stages that represent more intensive flow separation. Since the flow path design is mainly two-dimensional, and the hub section is the most loaded, the flow separation means higher load at this mode. This confirms the loading distribution on the Fig. 3.

The compressor map based on series of computations is presented on Fig. 5. The upper limit was defined as the maximum outlet static pressure when the computation converged. It is known that the computation model is highly sensitive to the mesh quality and turbulence modeling, but this configuration was widely tested by authors and proved its early surge character, so the computational surge limit expected to occur at $3.5 \%$ lower pressure ratio than it would be on the real engine. 
The V2 has lower surge limit at part modes, which is consistent with data shown above. Finally, V4 configuration was chosen as a base for further production and investigation due to its optimal surge limits and stage characteristics in the whole working range.

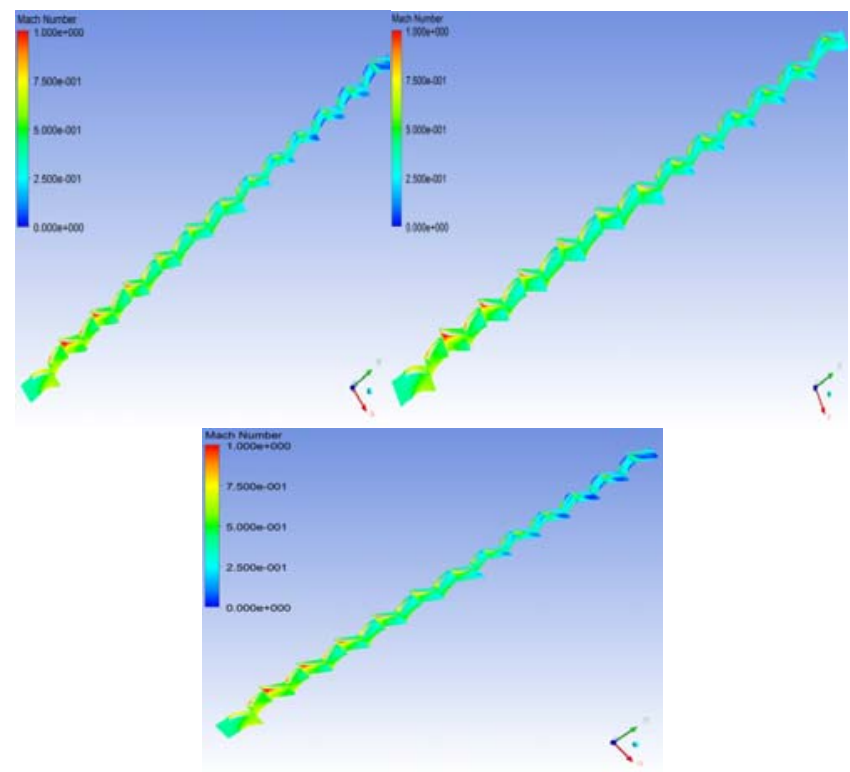

Figure 4: Mach number distributions for the datum compressor (top left), version 2 (top right) and 4 (bottom).

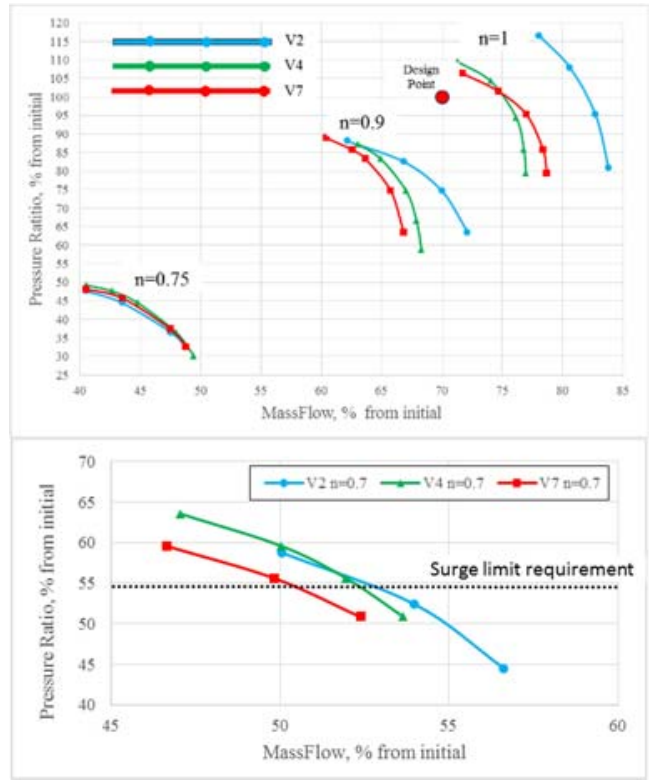

Figure 5: Compressor map for different flow path configurations 


\section{EXPERIMENTAL STUDY}

As a result, the real engine with re-machined compressor casing, new turbine and combustor modules were manufactured and installed on site. The pre-installed instrumentation of a gas turbine allowed measurements of mass-averaged performance parameters: the mass flow at the compressor inlet, total pressure at the inlet duct and combustor outer space (essentially after compressor) and also total pressure at the cooling air channel. The cooling air is extracted between two inner casing arrangements (after the 5th stage), so, measured pressure is considered as shroud static pressure after the 5th stage rotor blade (see Fig. 1). Similar approach was used during series of tests, described, for example in [7].

The measurement set allowed estimation of turbine power, unit efficiency, and some overall performance parameters of the compressor and the turbine. Control of pressure pulsations was arranged above the second and pre-last stage of the compressor with high frequency piezoelectric sensor in order to control aerodynamic stability via pressure pulsations on part modes.

As a result, final adjustment procedure was in need due to compressor/turbine missmatching. There were several reasons for that: lower than expected compressor adiabatic efficiency and lower than expected flow capacity of the high pressure turbine. As a result, the engine could not reach the required power at $100 \%$ speed. Also compressor stability was under concern.

In order to match compressor/turbine mass flow and consumed power two positions of compressor inlet guide vanes were tested together with two positions of first nozzle of the power turbine. Where the former were addressed to compressor air flow reduction and the latter was aimed to gain in high pressure turbine power. As a result, Fig. 6 represents the compressor adiabatic efficiency versus GT output power. The first number represents the Inlet Guide Vane position and the second is for power turbine nozzle. So for example, 0/+2 means the initial position of IGV and PT Nozzle opened by 2 degrees.

As a result, compressor efficiency went up to the expected level of 83 to $85 \%$ within the operating range. However, notable penalty in output power had to be accepted. Further work for better compressor-turbine matching is to be done after more detailed instrumentation and wider range of operating conditions to be studied. Installed piezoelectric sensors didn't show any significant pressure pulsations as possible blade resonance or rotating stall effects, so

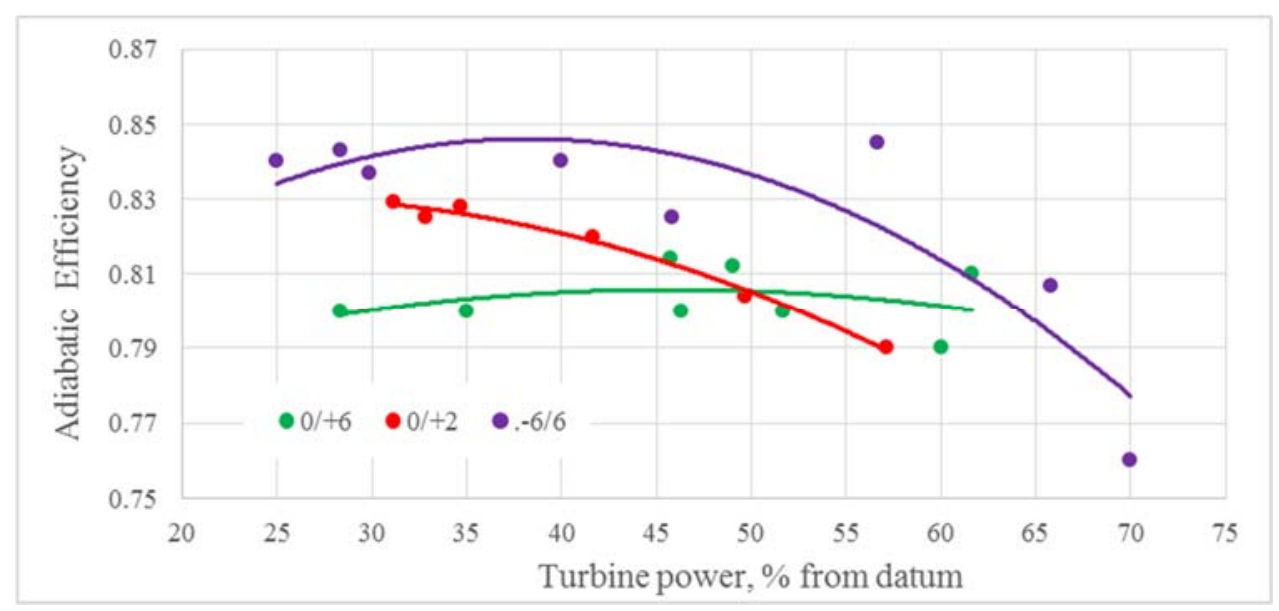

Figure 6: Compressor efficiency versus the GT power. 
both first and last stages are far away from stalling. Although, the measurement set used was insufficient to judge the detailed compressor behavior, the overall performance objectives were successfully achieved.

\section{CONCLUSIONS}

Mathematical modeling and CFD calculations were carried out in order to choose the optimum redesign configuration for axial compressor with reduced mass flow. The shroud contour effect on stage loading distribution and blockage was studied computationally. It is shown that even $2-3 \%$ change in blade height can significantly change the stage loading and compressor stall margin.

The correction of 5\% to the swept area was applied at the compressor exit in account for increased secondary losses and blockage. Maximum area correction was made at the rear group of stages, whereas for the frontal stages it was considered unnecessary.

Variations of the meridional contours showed drastic change in compressor performance, and due to insensitivity of the CFD models to many local flow features applied corrections might not be optimum in wide operating range. For the same reason fine tuning of the compressor model was skipped until further experimental data will be used for model validation.

As a result of the project, the redesigned compressor showed desired performance on site. However, more detailed instrumentation of the test compressor, such as casing static pressure measurements is planned in the nearest future for better tuning of the computational models. After final tests similar configuration is to be applied in 9 other machines.

\section{ACKNOWLEDGEMENT}

This article was prepared with the financial support of Competitiveness Enhancement Program - CEP 3.1.1.1-18.

\section{REFERENCES}

[1] Sedunin, V.A., Komarov, O.V., Blinov, V.L., Skorokhodov, A.V. \& Prokopetc, A.O., The application of modern Computational fluid dynamics techniques for increasing the efficiency and stability of an axial compressor in an industrial Gas Turbine. Energy Production and Management in the 21st Century, vol. 1. WIT Transactions on Ecology and the Environment, vol. 190, WIT Press, 2014.

[2] Danilishin, A., Kozhukhov, Y. \& Yun, V., Multi-objective optimization for impeller shroud contour, width of vane diffuser and number of blades of the centrifugal compressor stage based on the CFD calculation. 9th International Conference on Compressors and Their Systems) (City University London). Programme and Book Abstracts, p. 80, 2015.

[3] Ikeguchi, T. et al., Design and Development of a 14-Stage axial compressor for industrial gas turbine. Proceedings of ASME Turbo Expo 2012, Denmark, GT201268524.

[4] Wellborn, S.R. \& Delaney, R.A., 2001, "Redesign of a 12-Stage Axial-Flow Compressor Using Multistage CFD”, ASME 2001-GT-0351, presented at the ASME Turbo Expo: New Orleans, LA, 2001.

[5] Attia, M.S., Upgrade of a 16-stage industrial compressor, Part II: Extension of the analysis method to the design function and results. Proceedings of ASME Turbo Expo, Barcelona: Spain, GT2006-91199, 2006.

[6] Komarov, O.V., Sedunin, V.A., Blinov, V.L. \& Skorokhodov A.V., Parametrical diagnostics of gas turbine performance on side at gas pumping plants based on standard 
measurements. Proceedings of the ASME Turbo Expo: Turbine Technical Conference and Exposition, GT 2014, Dusseldorf, Germany, 16 June 2014 through 20 June 2014 Volume 3B, GT2014-25392.

[7] Sieverding, F., Casey, M., Ribi, B. \& Meyer, M., "Design of Industrial Axial Compressor Blade Sections for Optimal Range and Performance", ASME GT200338036. Presented at The ASME Turbo Expo 2003, Atlanta, GA, 2003.

[8] Larosiliere, L.M., Wood, J.R., Hathaway, M. \& Dang, T.Q., Aerodynamic Study of Advanced Multistage Axial Compressor, NASA TP-2002-211568.

[9] Alm-Eiden, A.M., Abdel Gawad, A. F., Hafaz, G. \& Abd El Kreim, M.G., Design and Optimization of a Multi-Stage Axial Flow Compressor. ICFD11-EG-4103. Proceedings of ICFD11: Alexandria, 2013. 